\title{
Communication Network Analysis of Negative Campaigns on \#BapakHoaxNasional in the 2019 Presidential Election
}

\author{
Ali Al Harkan ${ }^{1, *}$ Anggun Nadya Fatimah ${ }^{2,}$ Dyah Permana Erawaty ${ }^{3}$
}

\author{
${ }^{1}$ University of Indonesia \\ ${ }^{2}$ University of Indonesia \\ ${ }^{3}$ University of Indonesia \\ *Corresponding author. Email: ali.al81@ui.ac.id
}

\begin{abstract}
The 2019 Indonesia presidential election took place both in real-life and virtual settings, including on social media. Among the many forms of discourse, expressing political views using a hashtag is common practice on Twitter. This communication network analysis research is conducted to describe the structure of a negative campaign network on \#BapakHoaxNasional on Twitter and the actor(s) with significant roles within that network. The results of this study show that this network has a low density, loose structure with low cohesiveness concentrated among five main actors: @jokowi, @jhrpujianto, @rfauzy5, @doddy_lukas_, and maktal_212, for the Mention and Reply Tweet network. The Twitter account @jokowi is the most significant actor, with the highest score on degree centrality, betweenness centrality, and eigenvector centrality.
\end{abstract}

Keywords: Communication Network Analysis, Indonesia Presidential Election 2019, Negative Campaign, Opinion Battle on Twitter

\section{INTRODUCTION}

From April 8 to 17, 2019, Indonesia held its presidential election. This contest featured the two same candidates as the 2014 presidential election, Jokowi and Prabowo, and for the first time, the presidential election and the election of legislative members were simultaneous. The program stages and schedule for the implementation of the 2019 General Election were released in full by the General Election Commission (KPU), and political parties were banned from campaigning before the campaign period began, that is, involving the general public and social media. The Indonesian public agrees that many negative campaigns are good for political learning so that the shortcomings and weaknesses of the parties and candidates are revealed (Edo, 2014); thus, this article has a negative campaign context.

The popularity of Twitter usage in Indonesia shows a significant development. The community began to use Twitter as a source and/or means of sharing information. The number of Twitter users is increasing annually, and Twitter's number of users is equivalent to that of other social media. Twitter verifies its users: verified users indicate that the user account identity information is correct and demonstrates the credibility of the account. A well-managed Twitter account can reach and interact intimately with its audience. A follower account can see every tweet (a maximum of 140 characters) sent without exception, and the message delivered on Twitter is solid, informative, and casual, inviting people to interact with the tweet.

Ibnu Aziz (2014) said (Budiyono, 2015, p. 145) that research on the content of media had been carried out by Masyarakat Peduli Media (MPM), a nongovernmental organization in Yogyakarta. The results of the study found that most conversations by supporters of the presidential candidate were only negative or black campaigns. MPM Yogyakarta stated that out of 1,541 Twitter conversations of supporters of presidential candidates in the 2014 general election, approximately 1,300 (or $86.4 \%$ ) were negative and disfavored the presidential and other vise presidential candidates who were not their choices; only $13.6 \%$ of these Twitter conversations were positive. 
A movement has actors spread information so that a communication network pattern is formed as part of collective action. \#BapakHoaxNasional or \#koalisiprabohong is evidence of a negative campaign through Twitter, a social media platform. However, the identity of the actor who communicated information about and influenced the 2019 presidential election on Twitter and their relation to the emergence of the hashtags remains unknown.

One form of social media that can be analyzed by social network analysis (SNA) is the communication network on political topics related to Indonesian democratic parties through \#bapakhoaxnasional or \#koalisiprabohong as a form of a negative campaign. SNA or the SNA technique finds patterns of interaction between social actors in social networks. SNA can empirically uncover organizational networks, identify central individuals, find patterns of interaction, and detect subgroups (Lu et al, 2010, p.31-41).

Two main factors are thought to influence the possibility of negative campaign practices. First, community political participation has not been accompanied by a good level of political literacy. Second, the rapid development of the internet has become a forum for political parties and supporters of each presidential candidate to campaign on social media, especially on Twitter. Because of the characteristics of Twitter, these messages spread easily at all levels of society without the limitations of space and time and provide the opportunity to participate in campaign activities. Thus, a conclusion is that Twitter as a social media platform plays a critical role in political campaigns.

Based on observations of Twitter, some accounts claim to be supporters of certain presidential candidates. These accounts actively spread tweets on clickbait topics related to the support of and opposition to presidential candidates. Not infrequently, the posts on these topics lead to negative campaigns.

This study asks two research questions: Who are the main actors involved in the negative campaign communication network on Twitter, and what are the characteristics of the negative campaign communication network structure? The purpose of this study is to describe the network structure and interaction between actors in the network related to the negative campaign of the 2019 presidential election on Twitter from November 20 to 30, 2018, with the hashtag \#bapakhoaxnational, which includes: a. The main actor (account on Twitter) involved in the \#bapakhoaxnasional negative campaign for the 2019 presidential election campaign period, and b. A review of the structure in the network to determine the characteristics of the network structure.
The results of this study are expected to enrich the research on communication network analysis, especially in the field of political communication related to the campaign; and practically, the results are expected to be input for government agencies formulating policies against and educating the public about negative campaigns in social media.

Researchers have mentioned that social media has potential as a means of political communication; however, communication by users has been debated (Budiyono, 2015, p. 145). Social media can be developed as a media platform that improves political communication by using ethical language (Budiyono, 2015 , p. 145). Conversation characteristics have been observed in the use of social media networks for political participation (Adianto, 2010). Three motivations of social media users are used to increase political participation: economic, state task, and social care (Adianto, 2010). The following were used in the 2017 General Election of DKI Jakarta: data crawling systems, preprocessing, manual class collection, weighting, training data for testing and testing data with vector engine support, collecting data chirping with black campaign elements, and data chirping without black campaigns (Sa'diyah, 2017). Social media platforms (1) are effective tools for political campaigns, (2) reach out to voters and direct supporters, (3) are used by political parties to determine party attributes, and (4) are used by political parties that use social media to win legislative elections (Abdillah, 2014, pp. 1-10). No network analysis research on Twitter has investigated negative campaigns.

\section{STYLE PALETTE}

\subsection{Negative Campaign}

Negative campaigns differ from dirty tricks, fraud, or cheating. This action is a campaign violation and is included in illegal acts. The negative campaign in this study was not included in this category. According to Mark (2007), a negative campaign regarding the actions of candidates who want to win the general election by attacking the opponent rather than emphasizing the opponent's positive side and policy. This form of negative campaign is an over-telling of the bad history of the opponent and a description of the opponent's irregularities or errors by using verbal or physical language. John G. Geer argued that negative campaigns are criticisms launched by a candidate (or group of supporters) during the campaign (Geer, 2008). Furthermore, Lilleker argued that negative campaigns are a form of communication that emphasizes the weaknesses of opponents' arguing, behaving, personality, and ability to govern. Most candidates make negative references about their political opponents in general elections. Negative campaigns are divided based 
on the arguments delivered in the message into three types: (1) direct attack, (2) direct comparison, and (3) implied comparison (Johnson-Cartee and Copeland, 2013).

\subsection{Twitter}

Twitter is a social networking and microblogging service founded by Biz Stone, Evan Williams, and Jack Dorsey in 2006. This social media platform allows users to send and read text-based messages of up to 280 characters, known as a tweet. The number of active Twitter users has been 336 million per month. Some of the main features of Twitter include (1) Retweet. To share or re-upload a post from others so that it can be seen by all followers. The Retweet feature is usually symbolized by a reversible arrow at the bottom of the tweet. (2) Hashtags are words without spaces beginning with the "\#" sign and help track everyone who talks about it. The use of hashtags that are often in Twitter conversations can make the hashtag popular (trending topic). (3) Mention, namely, the mention of another Twitter user username on a tweet that can be seen by their followers. This feature helps users engage in an interaction on Twitter where all messages are public. (4) Reply is a reply from the public tweets directed at the tweet maker. The reply feature is intended to be a conversation. (5) Timeline is the homepage of Twitter that lists the chirps of the accounts that have been followed and displays chirps based on time sequences or tweets that are popular. (6) Following \& Followers is a list of accounts followed by the following users. By following an account, the user receives the latest tweets (updates) from the accounts followed. (7) Like is a feature that allows a user to "like" the chirping of other users and is marked with a heart icon. When a user likes a tweet, the tweet appears on the timeline of followers of users who like it as an activity, not as a sharing mechanism such as retweeting.

\subsection{Communication Network}

A communication network is a contact pattern is from the flow of messages and information between communicators through space and time (Monge, Contractor, P.S. and Contractor, N.S., 2003). When humans communicate, links are formed (Littlejohn and Foss, 2002). Communication always includes relationships because communication is always a "together" event, that is, a concurrent process of information sharing between two or more people (Monge, Contractor, P.S. and Contractor, N.S., 2003). In organizational relations, communication networks consist of interconnected individuals connected by patterned information flows. The concept of a message here must be understood in the broad sense of message referring to data, information, knowledge, images, symbols, and other symbolic forms that can be moved from one network point to another or can be formed together through network members. This network is formed in many types of contemporary organizations, including personal contact networks, information flows within and between groups, strategic alliances between companies, and global organizational networks (Monge, Contractor, P.S. and Contractor, N.S., 2003).

From a network perspective, Twitter is a social network, and this is indicated by the characteristics of human social networks, namely, the distribution of nonpower-law followers according to follower-following topology analysis. Additionally, the characteristics of social networks on Twitter are homophile, or the tendency of network actors with similar characteristics to communicate with each other (Kwak et al, 2010).

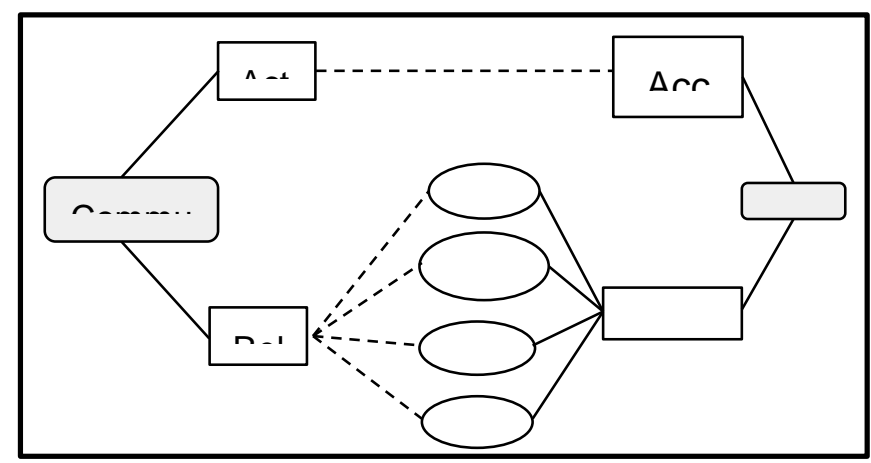

Figure 1 Conceptual Framework

\subsection{Method}

This research used a quantitative approach that built upon a positivistic paradigm. In this paradigm, social reality was treated in the same manner as natural reality, in which objectivity and quantitative measurement become substantial. Positivists believe in the presence of a general law underlying human behavior. Thus, by applying deductive logic and empirical observation, the casualization probability of human behavior can be confirmed and predicted (Neuman, 2011).

To answer the research questions, the communication network analysis method was adopted. This method attempts to describe and explain a social network and the structure of a network, in which the Twitter network was identified as the social network (Kwak et al, 2010). In this perspective, a network comprises the relationship among actors in a certain type of relationship (Eriyanto, 2014). Actors in this network can be individuals or, for example, an organization, company, or state. Relations are defined as a pattern of a relationship or interaction among actors in a specific network. A relationship is not an individual's property, but a character in which two or more people engage. Thus, a communication network can be interpreted as a developed structure built based on communication relationships (Monge, 1987, pp. 476478). In communication studies, this method is mainly 
applied to describe the communication structure within a network and the position of actors within that structure (Eriyanto, 2014).

This descriptive type of research is used to describe actors and structures of the object of study. Additionally, the object of this study is the network of the negative campaign on Twitter under \#BapakHoaxNational in the 2019 presidential election. The population of research comprises tweets under \#BapakHoaxNational on Twitter. Two parameters were used to define the population: the interaction on Twitter (mention, reply, or like activity) with \#BapakHoaxNasional embedded in it, and a negative campaign within that certain tweet. The sample in this research is limited to tweets uploaded within the period of research: November 20 to 30, 2018. This research used electronic documents as the data source; the data was gathered from Twitter in the form of mention, reply, and retweet activity. The researchers used crawling software provided by Netlytics.org. In the later stage, successfully crawled data were analyzed using Gephi software.

Although the implementation of software can productively assist researchers in gathering and managing electronic data, this strategy has several limitations. Due to the context of the study, the Netlytic software had two limitations. The first limitation is related to readable output. Four dimensions of interaction can be observed on Twitter: mention, retweet, reply, and like. Unfortunately, the software could only read three of the four: mention, reply, and retweet. The second limitation is related to the amount of data that can be crawled. Free Netlytic software can only crawl up to 1000 uploaded tweets. Therefore, only 1000 uploaded tweets in the form of mention, reply, and retweet were presented.

Another limitation was the change in policy from the Ministry of Communication and Information that erased radical content and sites from the network. This policy caused the number of available data to decrease. Despite the ability of free Netlytic software to crawl up to 1000 tweets, this policy drops decreased the amount of available data to approximately 400 uploaded tweets.

In this study, the level of analysis was operated on a structural and actor level. At the structural level, the focus of analysis was the network characteristics and structure. At the actor level, the analysis concentrated on the relations of actors within that network. This research applied different measurements to both levels. To analyze the structural level, three types of network measurements - density, centralization, and distancewere applied. Density refers to the intensity of communication among actors, centralization refers to a tendency to gather around specific actors, and distance refers to the longest distance between two actors in the observed networked (Eriyanto, 2014). To analyze the actor level, this research used centrality measurement. This measurement shows actors with a dominant position in a network. Four types of centrality measurement were applied: degree centrality, closeness centrality, betweenness centrality, and eigenvector centrality. In this stage, Gephi software was used to assist with data processing and to produce a sociogram of the observed network.

\section{RESULTS}

\subsection{Results: Twitter Data and Communication Network}

By using the Netlytic website, we crawled the data on December 1, 2018. The period specified in the Twitter dataset settings is set from November 5, 2018, until December 1, 2018, using the hashtag \#bapakhoaxnational. The data crawling process demonstrated the following: 397 tweets were distributed from November 20 to 30, 2018. These tweets were raw data that contained \#bapakhoaxnational, but not all were negative campaign tweets; thus, we carried out a cleansing process that removed six irrelevant pieces of data. Thus, 391 tweets were analyzed.

In addition to the data-cleansing process, we classified tweet topics based on general categories and categorized the types of network relations between actors based on the type of Twitter activity performed. This process resulted in the following groupings:

Table 1. Table of Tweet Classification by Topic

\begin{tabular}{|l|c|c|c|}
\hline & $\begin{array}{c}\text { Number of } \\
\text { Tweets }\end{array}$ & Category & Total \\
\hline Negative Speech & 228 & & \\
\cline { 1 - 2 } Economic Topics & 87 & Negative & 391 \\
\cline { 1 - 2 } $\begin{array}{l}\text { Personality } \\
\text { Topics }\end{array}$ & 33 & Campaign & \\
\cline { 1 - 2 } Lying Topics & 43 & Irrelevant & 6 \\
\hline Irrelevant Tweets & 6 & &
\end{tabular}

Table 2. Tweet Quantity Based on Relation Type

\begin{tabular}{|l|c|}
\hline \multicolumn{1}{|c|}{ Twitter Relations and Activities } & Total \\
\hline Relations Based on Reply Activities & 121 \\
\hline Relations Based on Retweet Activities & 203 \\
\hline $\begin{array}{l}\text { Relations Based on Retweet and Comment } \\
\text { Activities }\end{array}$ & 60 \\
\hline Relations Based on Mention Activities & 1 \\
\hline Actors without Relations & 20 \\
\hline
\end{tabular}


Based on the five types of Twitter activity identified (reply, retweet, retweet \& comment, mention, and without activity), communication network analysis was divided into two types of networks: Mention and Reply. A Mention network contained a network of actors based on Twitter activities of retweeting, retweeting \& commenting, mentioning, and the Reply network contained networks of actors based on Twitter reply activities.

The Mention network had 475 nodes and 705 edges, and the Reply network had 407 nodes and 607 edges. Actors who did not mention other accounts were identified as actors without relational activity, without lines connecting with other actors (20 tweets). Figures 2 and 3 present the sociograms of the two networks.

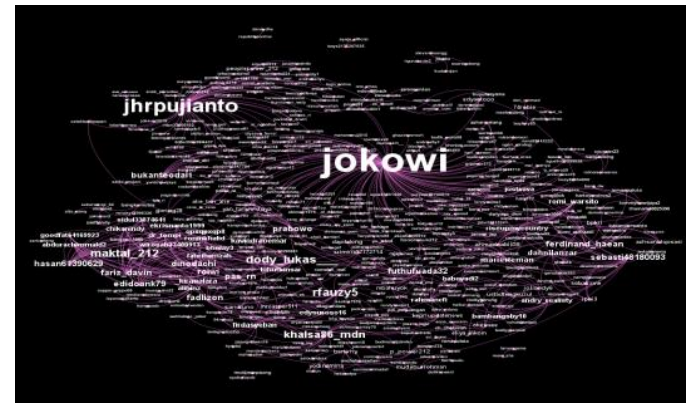

Figure 2 Sociogram of the \#bapakhoaxnational Hashtag Communication Network Based on Mention Activities.

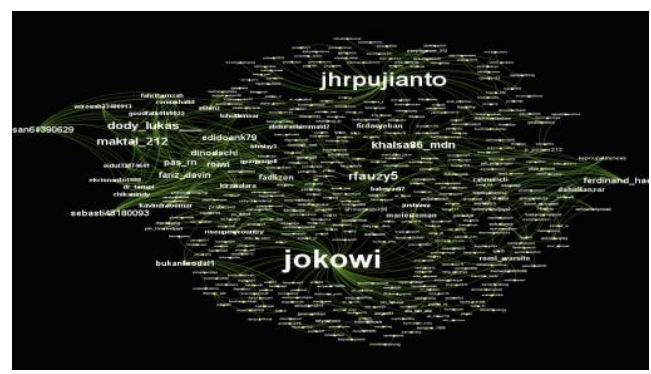

Figure 3 Sociogram of the \#bapakhoaxnational Hashtag Communication Network Based on Reply Activities

\subsection{Structural Level Network Analysis}

Network analysis on the structural level described three measurement dimensions: density, centralization, and diameter/distance. Every dimension is explained in this paper in the network of Mention Tweets and the network of Reply Tweets.

\subsubsection{Density}

Density refers to the intensity of communication among actors within the observed network. High density means communication occurs intensely, and low density means otherwise. Intensive communication is described as a greater number of actors linked to each other. High density can thus be understood as a situation in which the number of linked actors is higher than nonlinked actors, and vice versa. The threshold number is 0.5 . The closer the number is to 0 , the lower the density, and the closer the number is to 1 , the higher the density.

In this research, the sociogram shows 0.0006 for the network of Mention Tweets and 0.0007 for the network of Reply Tweets. Thus, the density of this network is extremely low. In the context of Twitter, this low density occurs because of reality, that is, many engaged actors can easily participate in conversations without knowing each other. In the context of \#BapakHoaxNasional, actors (Twitter users) mostly mention, retweet, or reply to one or more Twitter account(s); thus, they are only directly linked to the addressed actors. This pattern occurs in $99 \%$ of the total population, causing a low level of density.

\subsubsection{Centralization}

Centralization is a measurement dimension that represents the centrality tendency of a network based on a small number of actors. There are two categories of relational value: out-degree (OD) and in-degree (ID) value, and total value (TD) as the cumulation of both. OD value represents how many times an actor (user account) mentions or replies to others in the observed network. ID value represents how many times an actor is mentioned by others in the observed network. By optimizing Gephi software, this research maps five central actors for both Mention Tweets and Reply Tweets network.

For the network of Mention Tweets, the five central actors are users identified consecutively by these accounts: @jokowi $(\mathrm{TD}=104)$, @jhrpujianto $(\mathrm{TD}=$ 51), @ @rfauzy5 (TD = 26), @dody_lukas_, and @ maktal_212 (TD = 24 for each). The network of Reply Tweets shows an almost similar pattern as the one previously explained. Central actors are the same as in the Mention Tweets network, with slight differentiation in the number of value. Those central actors are $@$ jokowi $(\mathrm{TD}=69)$, jhrpujianto $(\mathrm{TD}=51)$, @ rfauzy5 $(\mathrm{TD}=26)$, @dody_lukas_, and @ maktal_212 (TD = 24 for each).

Among these users, the actor with the highest ID in the Mention Tweets and Reply Tweets network is $@$ jokowi, with ID $=104$ and OD $=0$ for the first network and ID $=69$ and $\mathrm{OD}=0$ for the second. The actor with the highest OD value in both networks is $@$ jhrpujianto, with ID $=0$ and $\mathrm{OD}=51$ for both networks. Thus, @ jokowi is the most mentioned actor, and @jhrpujianto is the most active actor in mentioning others. Central actors are actors with the highest number of relations within a network. 


\subsubsection{Diameter and Distance:}

Diameter refers to the longest distance between two actors in an observed network. Distance to the other side refers to the average path length needed by every actor to interact with each other. Diameter shows the many steps that a node (an actor) needs to interact with the farthest node in the network. Distance shows the average length needed by everyone to contact others in the network. Diameter and distance in a digital network can be found by using assisting software such as Gephi.

In this research, Gephi shows that the diameter in the Mention Tweets network is 13 , with an average path length of 4.8 as the measurement number for distance. For the Reply Tweets network, the diameter is 12 , and the distance shown by the average path length is 5.028. Diameter and distance help to understand the cohesivity level of a network. A high number for the diameter and distance, as aforementioned, can be interpreted as both networks having a loose structure and low cohesivity.

\subsection{Actor Level Network Analysis}

Network analysis on the actor level described four indicators: degree centrality, closeness centrality, betweeness centrality, and eigenvector centrality. Every indicator is explained in the following sections of this paper: network of Mention Tweets and network of Reply Tweets.

\subsubsection{Degree Centrality}

Of the 475 actors (nodes) in the mention network, @jokowi had the highest degree centrality, which was worth 104. The central value of the 104 level was the aggregate of the OD and ID. If interpreted, the OD value of Gephi processing is the number of times an account mentions other accounts in the network, and the ID is the number of times an account is mentioned by another account in the network. The total yield of Gephi processing shows that the value of 104 in the centrality of the @jokowi account's level is 104 ID and 0 OD. Thus, @jokowi is an account in the \#bapakhoaxnational Twitter communication network mentioned by other accounts 104 times; however, @jokowi did not mention other accounts. Based on 407 actors (nodes), @jokowi is the actor with the highest degree of centrality in the reply network, with a value of 69 . Based on the results of the aggregate value of the OD and ID, 69 is only obtained from the ID, and the OD in the reply network has only zero values.

\subsubsection{Closeness Centrality (Normalized)}

Closeness centrality shows how close the actor (node) is to all other actors in the network, or generally how close the actor is to the center of the network, because actors have a distribution that converges at the center of the network. Based on the processing of data using Gephi, 196 nodes (actors) had 1 as the value of closeness centrality. Thus, 196 actors in the Twitter communication network \#bapakhoaxnational are connected directly to the network center. Closeness centrality in the reply network has 14 nodes (actors) that have closeness centrality value 1 . This finding shows that 14 actors in the Twitter communication network \#bapakhoaxnational are close to all other actors in the network and connected directly to the network center. These 14 actors are also close to the center of the network because of a distribution pattern that collects at the center of the network.

\subsubsection{Betweenness Centrality (Normalized)}

Betweenness centrality describes the value of an actor in the network in connecting other actors who are more likely to be isolated to be able to connect with the network center. The results of Gephi processing demonstrated that in the Mention network, @jokowi has the highest value of betweenness centrality, which is 0.53 . The value of 0.53 is the value that goes through the normalization process; thus, the maximum absolute value is 1 . The higher the value of the betweenness centrality of an account, the higher the role of the actor in connecting other actors in the network. The results of the analysis of betweenness centrality in the reply network indicate that @jokowi has the highest betweenness centrality value, which is equal to 0.43 . The value of 0.43 is a normalized value; thus, it has a maximum absolute value of 1 .

\subsubsection{Eigenvector Centrality}

Eigenvector centrality describes actors who have relationships with important actors in the network. Based on the results of the processing data on 475 actors (nodes) using the Gephi application, the highest mention eigenvector centrality in the network is @jokowi,with a value of 1 . Thus, @jokowi is the actor most connected to the important actors in the network. In line with the explanations in the previous sections, this explanation is in line with the finding that @jokowi is the central actor (highest degree centrality value) most connected with actors in the network. The highest eigenvector centrality in the reply network is for @dody_lukas__ and @ maktal_212, with a value of 1 . The results of this analysis indicate that @doddy_lukas_ and @ maktal_212 are the most connected actors with the important actors in the network. The eigenvector centrality results based on the reply network are not in line with the reply centrality value of the reply network, that is, @jokowi is the central actor with the highest degree centrality value. 


\section{DISCUSSION}

In SNA, every node is considered an actor. A node is not necessarily a person and can be, for example, an institution, state, or city. How this character operates on Twitter is notable. On Twitter networks, the actor is represented by a username or Twitter account. A person can have more than one account, whereas a large organization can have only one official account. Another possibility is that the account(s) are be operated by a robot, called a bot.

In the Twitter network, actors do not always perform actions such as tweeting, replying, mentioning, or liking. Actors can also be passive, such as the ones that are being mentioned, liked, replied, or retweeted by other accounts within that network. This phenomenon also occurred under \#BapakHoaxNational. @Jokowi, the most significant actor with the highest degree of centrality, betweenness centrality, and eigenvector centrality in the Mention and Reply networks, is always passive.

Manual data analysis consists of mapping and data cleansing and shows that in this Twitter network, \#BapakHoaxNational was used mostly to attack @Jokowi. The majority of tweets revealing the negative aspects of President Jokowi, such as his failure to fulfill campaign promises related to economic development. These opinions are addressed to @ Jokowi, either by mentioning it directly or by retweeting or replying to tweets that had mentioned that account.

Although many tweets mention @Jokowi, the account remains silent. The Acting Head of Public Relations Bureau from the Indonesia Ministry of Information and Communication revealed this action as a communication strategy used by the incumbent president, Joko Widodo. The informant said that instead of responding to people's opinions through his Twitter account, President Jokowi prefers to reach a massive audience through mass media to speak once and be heard by many.

The result of the study shows that Twitter networks have similar and different characteristics from real-life social networks. Both networks have the same elements, namely, actors, relations, and conversations, but differ in the pattern of communication. In a real-life network, people commonly reach individuals they know. To reach individuals they do not know in real-life settings, people can ask an acquaintance to introduce them.

In SNA, this concept called six degrees of separation. This concept states that even in the largest network, anyone can be connected through the help of no more than five intermediaries' acquaintances. Steps in this context can be interpreted as the number of contacts necessary to connect to the most unknown person in your life. However, in social media settings referred
Twitter, this does not always occur. Two strangers can be connected by mentioning each other's account directly.

In the \#BapakHoaxNational network, this type of connection also occurs. Accounts that mention @ Jokowi or other significant actors may not personally know the owner of the account they mentioned. Thus, the diameter of the structure in the observed network can be more than six steps. This communication pattern of the observed network differs from a real-life network setting (i.e., six degrees of separation).

\section{CONCLUSION}

The network of \#BapakHoaxNational shows that the structure of this network is low in density, loose in structure, and low in cohesivity. These findings reflect a situation in which the majority of actors do not communicate with each other because of the nature of Twitter, which facilitates connections among strangers. This study also shows that the network is centralized among five main actors for the Mention and Reply tweets network, with @jokowi identified as the most significant actor with the highest score of degree centrality, betweenness centrality, and eigenvector centrality. This study recommends that further research use a time-series to understand the dynamics of negative campaign battles in social media and to use it as valuable data for strategic communication purposes, such as digital public relations.

\section{ACKNOWLEDGMENTS}

Our gratitude goes to Ummi Salamah, Eriyanto, Pinckey Triputra, and lecturers at the University of Indonesia who discussed Quantitative Research Methods, for the guidance given to us in this research.

\section{REFERENCES}

[1] Abdillah, L.A. (2014) 'Social media as political party campaign in indonesia', June (12), p1-10.

[2] Adianto, A. P. (2010) 'Jejaring media sosial sebagai media partisipasi politik', Available at: http://lib.ui.ac.id/bo/uibo/detail.jsp?id=20329214\& lokasi=lokal

[3] Budiyono B. (2015) 'Fenomena komunikasi politik dalam media sosial', Jurnal Ilmu Pengetahuan Dan Teknologi Komunikasi, 17(2), p145.

[4] Edo. (2014) 'LSI Denny JA: kampanye negatif jelang pemilu makin marak', Detik News, 02 April [online]. Available at: https://news.detik.com/survei/d-2543358/lsi-dennyja-kampanye-negatif-jelang-pemilu-makin-marak (Accessed: 10 June 2019) 
[5] Eriyanto. (2014) Analisis jaringan komunikasi. Jakarta: Prenadamedia Group.

[6] Geer, J.G. (2008) In defense of negativity: attack ads in presidential campaigns. University of Chicago Press.

[7] Johnson-Cartee, K.S. and Copeland, G. (2013) Negative political advertising: Coming of age. Routledge.

[8] Kwak, H., Lee, C., Park, H. and Moon, S. (2010) What is Twitter, a social network or a news media. Raleigh.

[9] Littlejohn, S.W. and Foss, K.A. (2002) Theories of human communication. Cengage Learning.

[10] Lu, Y., Luo, X., Polgar, M. and Cao, Y. (2010) 'Social network analysis of a criminal hacker community', The Journal of Computer Information Systems, 51(2), p31-41.
[11] Mark, D. (2007) Going dirty: the art of negative campaigning. Rowman \& Littlefield.

[12] Monge, P.R. (1987). 'Prologue to the special issues', Communication Research, 14(5), p476478. https://doi.org/10.1177/009365087014005001

[13] Monge, P.R., Contractor, P.S. and Contractor, N.S. (2003) Theories of communication networks. USA: Oxford University Press.

[14] Neuman, W.L. (2011) Social research methods: qualitative and quantitative approaches. 7 th edn. Boston: Pearson.

[15] Sa'diyah, Y.S.H. (2017) 'Klasifikasi data twitter untuk mendeteksi tweet black campaign menggunakan support vector machine'. 